\title{
Protective immunity against Trichinella spiralis in mice elicited by oral vaccination with attenuated Salmonella-delivered TsSP1.2 DNA
}

\author{
Jie Feng Li ${ }^{1}$, Kai Xia Guo ${ }^{1}$, Xin Qi ${ }^{1}$, Jun Jun Lei ${ }^{1}$, Yue Han ${ }^{1}$, Shu Wei Yan ${ }^{1}$, Peng Jiang ${ }^{1}$, Chuan Yu², \\ Xiang Chao Cheng ${ }^{2}$, Zhong Quan Wang ${ }^{{ }^{*}}$ and Jing Cui ${ }^{*}$
}

\begin{abstract}
Trichinellosis is a worldwide important food-borne zoonosis caused mainly by ingesting raw or undercooked pork infected with Trichinella spiralis larvae. The development of vaccine is needed for preventing swine from Trichinella infection to ensure pork safety. Previous studies showed that T. spiralis serine protease 1.2 (TSSP1.2) is a vaccine candidate against Trichinella infection. In this study, the complete TsSP1.2 cDNA sequences were cloned into pcDNA3.1, and the rTsSP1.2 DNA was transformed into attenuated Salmonella typhimurium strain $\triangle$ cyaSL1344. Oral vaccination of mice with Salmonella-delivered rTsSP1.2 DNA vaccine induced an obvious intestinal mucosal IgA response and a systemic Th1/Th2 immune response; the vaccinated mice showed a 33.45\% reduction of intestinal adult worms and $71.84 \%$ reduction of muscle larvae after T. spiralis larval challenge. The protection might be due to the rTsSP1.2induced production of specific anti-TsSP1.2 slgA, lgG, IgG1/lgG2a, and secretion of IFN- $\gamma$, IL-4 and IL-10, which protected intestinal mucosa from the parasite invasion, inhibited worm development and reduced female fecundity. The results indicate that the attenuated Salmonella-delivered rTsSP1.2 DNA vaccine offers a prospective strategy for the prevention and control of animal Trichinella infection.
\end{abstract}

\section{Introduction}

Trichinellosis, an important food-borne zoonosis worldwide, is principally caused by the parasitic nematode Trichinella spiralis [1]. T. spiralis infection is acquired mainly from ingesting raw or semi-cooked meat contained with the encapsulated infective muscle larvae (ML). Domestic pork is a major source of this infection in southern America, Southeast Asia, China and other countries [2-5]. In China, 12 trichinellosis outbreaks caused by eating contaminated pork were recorded from 2004 to 2009 [6]. Trichinella infection in domestic pigs has a serious impact on meat safety and public health [7]. Because a large amount of pork was consumed in the world, the

\footnotetext{
*Correspondence: wangzq2015@126.com; cuij@zzu.edu.cn

${ }^{1}$ Department of Parasitology, Medical College, Zhengzhou University, Zhengzhou 450052, China

Full list of author information is available at the end of the article
}

development of vaccine is needed for preventing swine from Trichinella infection to ensure pork safety [8-10].

After infected meat is ingested, ML are liberated from the capsule in the host's stomach, where they develop into intestinal infective larvae (IIL) in the small intestine, before invading the intestinal mucosa where they develop into adult worms (AW) after undergoing four molts [11]. The AW dwell in the small intestine with their head burrowing into the intestinal epithelium, and ovoviviparous female adults deposit the newborn larvae (NBL) which penetrate into intestinal mucosa and migrate to skeletal muscles, where they become the encapsulated ML. The IIL invasion of host intestinal mucosa is the key step in the process of this infection. The intestinal mucosa is the first natural barrier to resist Trichinella invasion and the primary interaction location for the intestinal parasitic nematode and host [12]. Hence, it is important to elicit 
local intestinal mucosal immune response for immune protection against intestinal Trichinella infection [13].

In our previous studies, a $T$. spiralis serine protease 1.2 (TsSP1.2) (GenBank Accession No. EU302800) was identified in excretory-secretory (ES) and surface proteins of T. spiralis ML and IIL by immunoproteomics [14-17]. The bioinformatics analysis demonstrated that the complete cDNA sequences of TsSP1.2 gene are $1137 \mathrm{bp}$. The TsSP1.2 open reading frame (ORF) encodes a $35.5 \mathrm{kDa}$ protein of 313 amino acids. The signal peptide is located between 1 and 27aa. The TsSP1.2 has a domain of trypsin-like serine protease. The TsSP1.2 gene was cloned and expressed in our laboratory. Partial inhibition of larval invasion of intestinal epithelial cells (IEC) was observed using anti-TsSP1.2 serum; immunization of mice with rTsSP1.2 producing a partial immune protection against $T$. spiralis infection [18]. In the present study, a DNA vaccine targeting TsSP1.2 was delivered by attenuated Salmonella typhimurium strain $\Delta$ cyaSL1344. Local mucosal and systemic immune responses were investigated in mice vaccinated orally with Salmonella-delivered TsSP1.2 DNA vaccine, and protection against larval challenge was also evaluated.

\section{Materials and methods \\ Mice and parasite}

Female 5-week old BALB/c mice were provided by the Experimental Animal Center of Zhengzhou University (Zhengzhou, China). These mice were bred in individual ventilated cages (IVC, Suzhou Fengshi Laboratory Animal Equipment Co., Ltd, Suzhou, China). T. spiralis strain (ISS534) was obtained from a domestic pig in central China. We kept this strain by passages in BALB/c mice every 6 months.

\section{Collection of various worm stages}

The ML were acquired from experimentally $T$. spiralisinfected mouse carcass at 42 days post-infection (dpi) using an artificial digestion method $[19,20]$. The IIL were harvested from infected mouse intestines at 6 hours post-infection (hpi) [15], and the adult worms (AW) were respectively separated from intestines at 3 and $6 \mathrm{dpi}$ [21]. The newborn larvae (NBL) were collected from the 6 dpi female adults which were cultured in RPMI-1640 media for $24 \mathrm{~h}$ at $37^{\circ} \mathrm{C}$ [22].

\section{Attenuated Salmonella strain}

The attenuated S. typhimurium $\Delta$ cyaSL1344 strain in which the cya gene was deleted was prepared by the Animal Disease and Public Health Key Laboratory, Henan University of Science and Technology. The attenuated Salmonella strain was grown in Luria-Bertani (LB) broth containing $2 \% \mathrm{NaCl}[10]$ and applied as a vector of the expression plasmid pcDNA3.1 carrying TsSP1.2 gene.

\section{Plasmid construction and transformation}

The complete TsSP1.2 cDNA sequence was amplified by PCR using the following primers: 5'-TAAGCTTGCC ACCATGAAACGCTGGCAC-3', 5'-CTTCTCGAGTTA GCCGGCAT GCAGCAGT-3'. The HindIII and XhoI sites are bold. The amplified DNA fragment were cloned into pcDNA3.1 (Invitrogen, Carlsbad, USA). The insert sequence and ORF was verified by two directional DNA sequencing. The recombinant pcDNA3.1-TsSP1.2 and the control empty plasmid pcDNA3.1 were electroporated into the bacteria [10]. The transformant was selected on LB agar with $50 \mu \mathrm{g} / \mathrm{mL}$ ampicillin and identified by PCR amplification with restriction enzyme digestion and DNA sequencing (GENEWIZ, Suzhou, China).

\section{Preparation of recombinant TsSP1.2}

The rTsSP1.2 protein was expressed in an Escherichia coli BL21 (DE3) and identified in our laboratory [18]. The purified rTsSP1.2 had a molecular weight of $78.5 \mathrm{kDa}$ and consisted of a $35.5 \mathrm{kDa}$ TsSP1.2 protein and a maltosebinding protein tag $(43 \mathrm{kDa})$. An amylose pre-packed column (NEB Ltd, China) was utilized for purification of rTsSP1.2 [23].

\section{RT-PCR and immunofluorescent test (IFT) for detecting the in vitro transcription and expression of TsSP1.2}

Baby hamster kidney cell 21 (BHK-21) were cultured in plates with DMEM media supplemented with $100 \mathrm{U} / \mathrm{mL}$ penicillin, $100 \mu \mathrm{g} / \mathrm{mL}$ streptomycin and $10 \%$ inactivated fetal bovine serum (FBS) at $37{ }^{\circ} \mathrm{C}$ in $5 \% \mathrm{CO}_{2}$. When the BHK 21 cells were grown to $90 \%$ confluence, the cells were collected by trypsinization and transfected with pcDNA3.1-TsSP1.2 with a cationic lipid Lipofectamine 2000 (Invitrogen, USA) at the ratio of $0.8 \mu \mathrm{g}$ DNA: $2 \mu \mathrm{L}$ lipid per well in serum-free DMEM media at $37{ }^{\circ} \mathrm{C}$ for $48 \mathrm{~h}$. Total RNA was extracted from the BHK-21 cells $24 \mathrm{~h}$ after transfection, and the transcription levels of TsSP1.2 mRNA in transfected cells were assayed by RTPCR with TsSP1.2-specific primers as listed above [24]. Expression of TsSP1.2 protein in cells was observed using IFT [25]. Briefly, BHK-21 cells were cultivated as monolayers and fixed with cold acetone for $15 \mathrm{~min}$. After being washed with PBS, the cells were blocked with 5\% normal goat serum at $37^{\circ} \mathrm{C}$ for $1 \mathrm{~h}$, and then probed with 1:10 dilutions of mouse anti-rTsSP1.2 sera at $4{ }^{\circ} \mathrm{C}$ overnight. Then, the cells were incubated with a 1:100 dilution of anti-mouse IgG-FITC conjugate (Santa Cruz Biotechnology, Dallas, Texas, USA) for $1 \mathrm{~h}$ at room temperature. The cells were stained by $0.01 \%$ Evans blue for eliminating non-specific staining. Finally, the cells were observed and photographed by fluorescence microscopy (Olympus, Japan). 


\section{Immunization design and sample collection}

One hundred and twenty mice were divided into 3 groups (40 mice per group). On day 0 , the immune group of mice was infused orally with $1 \times 10^{8}$ cells of $\Delta$ cya SL1344/ pcDNA3.1-TsSP1.2. The empty $\Delta c y a S L 1344 /$ pcDNA3.1 or PBS was given orally to control mice. All mice were boosted two times at a 10-day interval. Before oral inoculation, all mice were infused by gavage with $100 \mu \mathrm{L}$ of $10 \% \mathrm{NaHCO} 3$ for neutralizing stomach acidity [26]. At days $0,10,20$ and 30 after immunization, blood samples were collected from 10 mice of each group. Five mice from each group were euthanized, and small intestines, spleens and mesenteric lymph nodes (MLN) were taken to assay the immune responses.

\section{RT-PCR and IFT for detecting the in vivo transcription and expression of TsSP1.2}

At 1-week post last immunization, TsSP1.2 mRNA was detected in spleens and MLN of vaccinated mice by RTPCR with TsSP1.2-specific primers as mentioned above. Total RNA of spleens and MLN was prepared using TRIzol (Invitrogen, Carlsbad, USA). Mouse $\beta$-actin of spleens and MLN was also amplified as an internal control [27]. PCR product was electrophoresed with $1 \%$ agarose gels. To determine the TsSP1.2 expression in vivo, the spleens and MLN of mice vaccinated with TsSP1.2 DNA vaccine were fixed and microtomed with thickness of $5 \mu \mathrm{m}$. The IFT was performed as described above [25]. The only difference was that the frozen section was not stained with Evans blue.

\section{Determination of anti-rTsSP1.2 lgG and its subclass by ELISA}

Specific anti-rTsSP1.2 antibodies (total IgG, IgG1 and IgG2a) in serum of vaccinated mice were measured by standard indirect ELISA at 10 days following each vaccination $[28,29]$. Microtiter plate was coated with rTsSP1.2 $(2 \mu \mathrm{g} / \mathrm{mL})$ at $4{ }^{\circ} \mathrm{C}$ overnight. After being washed, $5 \%$ skim milk was utilized for blockage at $37{ }^{\circ} \mathrm{C}$ for $2 \mathrm{~h}$, and incubated with 1:100 dilutions of mouse sera. After being washed again, the plate was incubated with HRPconjugated anti-mouse IgG, IgG1, or IgG2a (1:5000; Sigma-Aldrich). The coloration was developed by incubation with $o$-phenylenediamine dihydrochloride (OPD; Sigma) plus $30 \% \mathrm{H}_{2} \mathrm{O}_{2}$. The absorbance at $490 \mathrm{~nm}$ was determined by a microplate reader (Tecan, Schweiz, AG, Switzerland).

Determination of total and TsSP1.2-specific secretory $\lg \mathrm{A}$ To determine total and TsSP1.2-specific secretory IgA (sIgA) response, the intestinal washes were prepared
[30]. Briefly, small intestine was cut into $10 \mathrm{~cm}$ long for each vaccinated mouse, and the intestinal interior was douched three times with $1 \mathrm{~mL}$ of cold PBS. After intestinal washing, the intestinal contents were centrifuged at $7300 \mathrm{~g}$ for $10 \mathrm{~min}$ and the supernatant was collected. Intestinal secretory total IgA was determined by sandwich ELISA as described [10]. TsSP1.2-specific IgA was assayed by indirect ELISA using rTsSP1.2 $(2 \mu \mathrm{g} / \mathrm{mL})$ as the coating antigen.

\section{Recognition of native TsSP1.2 at different $T$. spiralis phases by IFT}

Native TsSP1.2 on the surface and internal structures of various T. spiralis phases was observed by IFT with antiTsSP1.2 serum and TsSP1.2-specific sIgA in intestinal washes from vaccinated mice [31, 32]. The intact worm or $2-\mu \mathrm{m}$ sections of different stages was fixed in cold acetone, anti-TsSP1.2 serum or intestinal washes from vaccinated mice were used as primary antibody, and anti-mouse IgG- or IgA-FITC conjugate (1:100 dilution, Abcam, UK) served as the secondary antibody. After incubation and washing, intact worms and sections were observed by fluorescent microscopy (Olympus, Japan) $[33,34]$.

\section{Cytokine assays}

The cells of spleen and MLN were harvested from immunized and non-immunized mice on days 0, 10, 20 and 30 after vaccination $[10,33]$. Cell suspensions were prepared and their density was diluted to $2 \times 10^{6}$ cells $/ \mathrm{mL}$ in complete RPMI-1640 containing 10\% FBS. Cell suspensions were cultured and stimulated with the rTsSP1.2 $(4 \mu \mathrm{g} / \mathrm{mL})$ in a humidified $5 \% \mathrm{CO}_{2}$ atmosphere for $72 \mathrm{~h}$ at $37{ }^{\circ} \mathrm{C}$. Non-stimulated cells were used as a negative control. Cytokines (IFN- $\gamma$, IL-4, and IL-10) in supernatant were assayed by ELISA and cytokine concentration was shown as $\mathrm{pg} / \mathrm{mL}$ [35].

\section{Immune protection against challenge infection with $T$. spiralis}

To assess the immune protection, 20 mice from each group were challenged orally with $300 \mathrm{~T}$. spiralis $\mathrm{ML}$ 7 days after the third vaccination, euthanized at $7 \mathrm{dpi}$, and adult worms of small intestine were recovered and numerated [32]. The length of female adults was measured under light microscopy. The fecundity of adult females was determined after being incubated in 1640 medium for $72 \mathrm{~h}$ at $37{ }^{\circ} \mathrm{C}$, and the NBL born by each female was numerated [36]. The muscle larval burden of the remaining mice were examined by artificial digestion method at 35 dpi [37]. Immune protection was evaluated as the worm burden reduction of intestinal adults and muscle larvae collected from the group vaccinated with 
$\Delta$ cyaSL1344/pcDNA3.1-TsSP1.2 with respect to those from the control mice that received only PBS $[38,39]$.

\section{Statistical analysis}

All the data was analyzed with SPSS version 17.0 software. The data were shown as the mean \pm standard deviation. The intra- and intergroup statistical analysis were performed with one-way ANOVA (LSD test). $P<0.05$ was regarded as statistically significant.

\section{Results}

\section{Construction of recombinant pcDNA3.1-TsSP1.2}

The complete TsSP1.2 cDNA was cloned into pcDNA3.1. After being digested with HindIII and XhoI, an approximately 948 bp insert was observed in recombinant
pcDNA3.1-TsSP1.2. Sequencing results revealed that the amplified TsSP1.2 fragment consisted of $948 \mathrm{bp}$, the predicted ORF encoded a protein of 315 amino acids of $35.2 \mathrm{kDa}$, with $99.58 \%$ identity to those of TsSP1.2 in GenBank (EU302800).

\section{The in vitro transcription and expression of TsSP1.2}

TsSP1.2 mRNA transcription in BHK-21 cells was assayed using RT-PCR. An amplified TsSP1.2 fragment was detected in cells transfected with pcDNA3.1-TsSP1.2, but not in cells transfected with empty pcDNA3.1 and nontransfected BHK-21 cells. TsSP1.2 protein expression in BHK-21 cells was observed by IFT using anti-rTsSP1.2 serum, intense immunostaining was detected in transfected cells, but not in non-transfected cells (Figure 1).
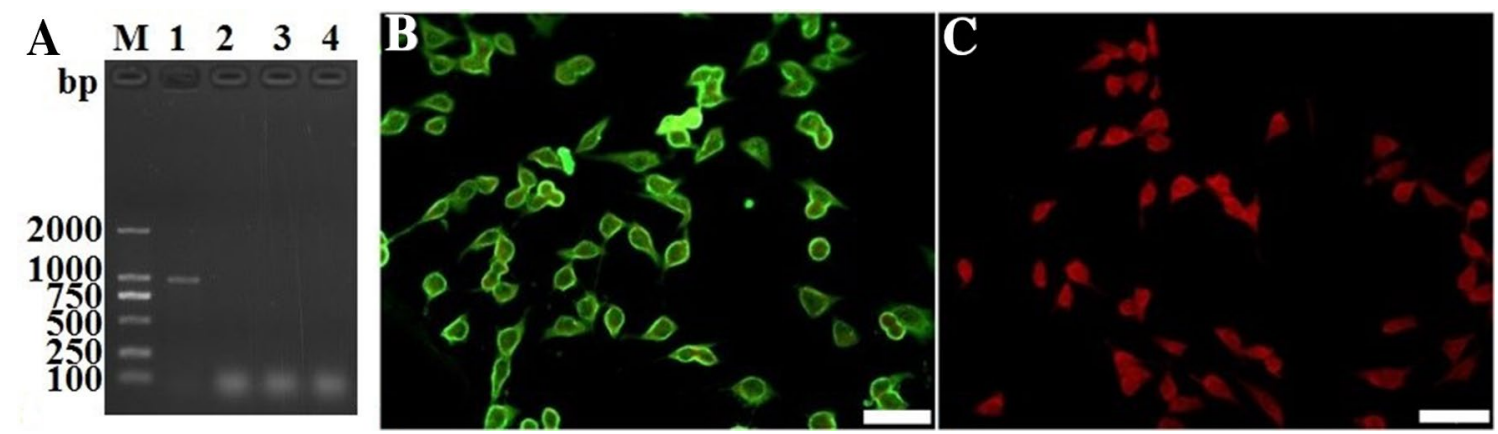

Figure 1 The in vitro transcription and expression of TsSP1.2 in transfected BHK-21 cells. A TsSP1.2 mRNA transcription in BHK-21 cells was detected by RT-PCR. I. M: DL2000 marker; 1: pCDNA3.1-TsSP1.2 transfected cells; 2: empty pcDNA3.1 transfected cells; 3: non-transfected normal cells; 4: Lipofectamine 2000 control. B TsSP1.2 expression in BHK-21 cells transfected with pcDNA3.1-TsSP1.2 was observed by IFT with anti-rTsSP1.2 serum. C The pcDNA3.1-transfected BHK-21 cells were used as negative control. The scale bar is $50 \mu \mathrm{m}$.

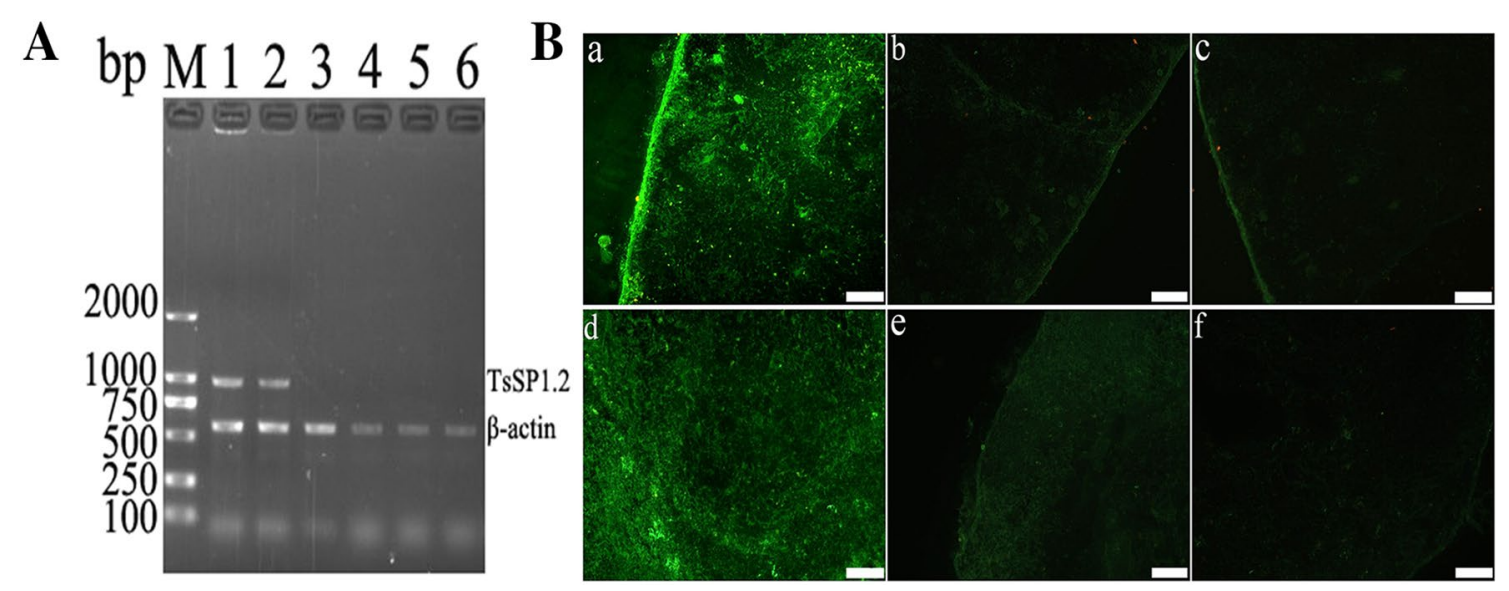

Figure 2 The in vivo transcription and expression of TsSP1.2 in mice vaccinated with TsSP1.2 DNA/S. typhimurium. A RT-PCR analysis of TsSP1.2 mRNA transcription. TsSP1.2 mRNA was detected in spleen (lane 1) and MLN (lane 2) of TsSP1.2-immunized mice, either in spleen (lane 3) or in MLN (lane 4) of mice vaccinated with only empty pcDNA3.1, not in spleen (lane 5) and MLN (lane 6) of mice inoculated with only PBS. B IFT detection of TSSP1.2 expression. The expression of TSSP1.2 was detected in spleen (a) and MLN (d) of TsSP1.2-immunized mice by IFT with anti-rTsSP1.2 serum, but not in spleen (c) and MLN (f) by IFT with pre-immune serum. By using anti-rTsSP1.2 serum, no distinct staining was observed in spleen (b) and MLN (e) of mice inoculated with only empty pcDNA3.1. Scale bar: $100 \mu \mathrm{m}$ 


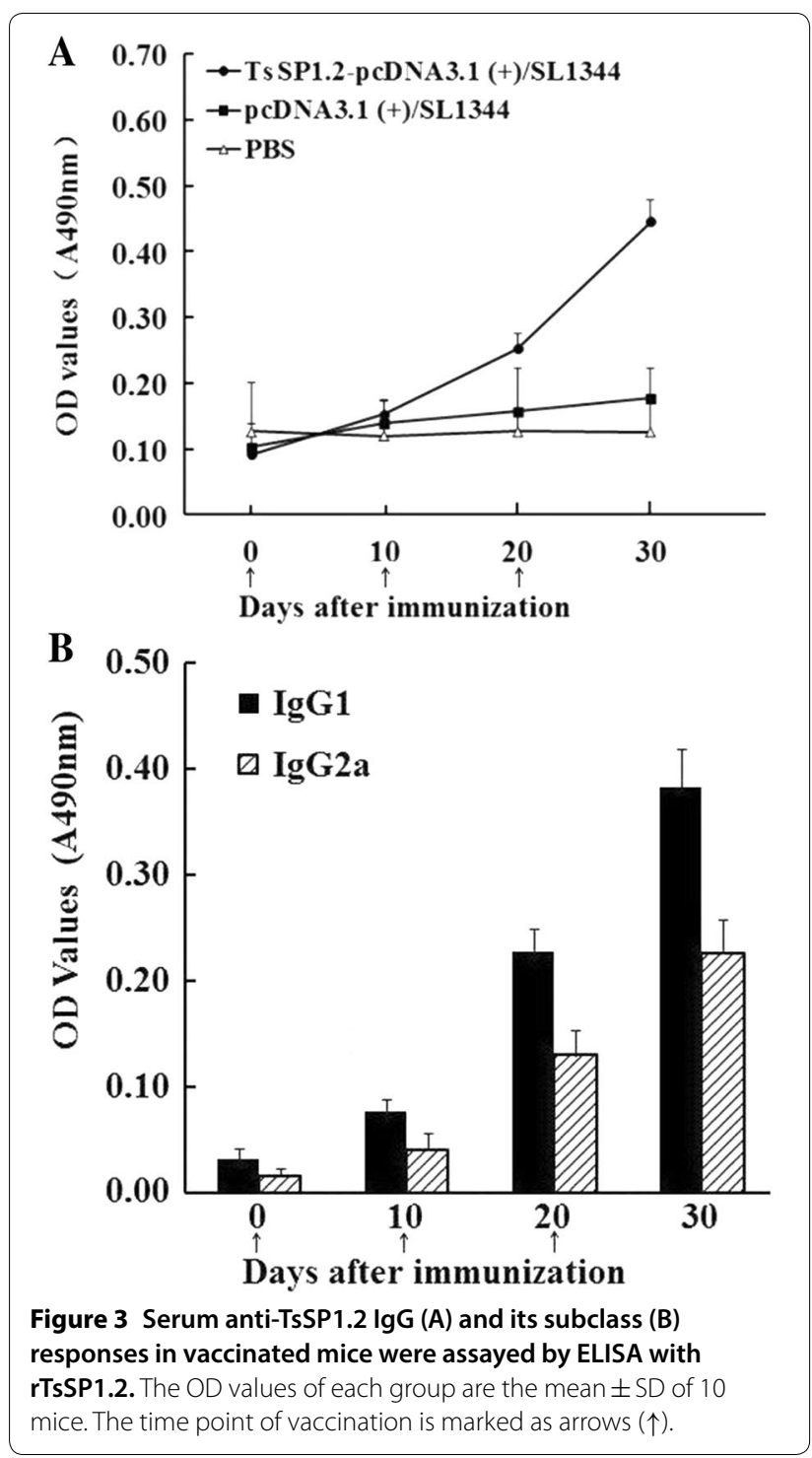

The in vivo transcription and expression of TsSP1.2

To determine the transcription of TsSP1.2 in the spleen and MLN tissues of vaccinated mice, total RNA was extracted from spleen and MLN, TsSP1.2 mRNA transcription was detected by RT-PCR in mice vaccinated with TsSP1.2 DNA vaccine, but not in mice inoculated with only empty pcDNA3.1. Murine $\beta$-actin cDNA was also amplified as an internal control. Immunostaining was detected in spleen and MLN tissue sections of mice vaccinated with TsSP1.2 DNA vaccine using IFT with anti-rTsSP1.2 serum but not in mice inoculated with only empty pcDNA3.1. When pre-immune serum was used, no evident staining was seen in tissue sections of vaccinated mice (Figure 2). The results revealed that TsSP1.2 was transcribed and expressed in mice vaccinated with $\Delta$ cyaSL1344/pcDNA3.1-TsSP1.2.
Systemic humoral immune responses

Serum anti-TsSP1.2 IgG and its subtype (IgG1 and IgG2a) at 10 days after each immunization were assayed by ELISA. Anti-TsSP1.2 IgG levels in mice vaccinated with TsSP1.2 DNA/S. typhimurium was obviously elevated after the $2^{\text {nd }}$ and $3^{\text {rd }}$ vaccination (Figure $3 \mathrm{~A}$ ). But, two groups of mice inoculated with empty pcDNA3.1or PBS did not exhibit apparently detectable anti-TsSP1.2 IgG responses. To evaluate the ability of the TsSP1.2 DNA vaccine to elicit Th1 or Th2-like responses, serum level of anti-TsSP1.2 IgG subclass was also determined. The level of anti-TsSP1.2 IgG1 and IgG2a was also elevated evidently in mice vaccinated with TsSP1.2 DNA/S. typhimurium after the $2^{\text {nd }}$ and $3^{\text {rd }}$ vaccination (Figure 3B). The IgG1 level on day 20 and 30 following the first vaccination was distinctly higher than those of IgG2a $\left(\mathrm{t}_{20 \text { days }}=10.527, \mathrm{t}_{30 \text { days }}=10.971, P<0.01\right)$. Nonetheless, it is obvious that IgG2a was also triggered after the third vaccination, demonstrating that the concurrent Th1/Th2 immune response was elicited by immunization with TsSP1.2 DNA/S. typhimurium.

\section{Cytokines from TsSP1.2-stimulated spleen and MLN cells of vaccinated mice}

To evaluate the cytokine production induced by vaccination with $\Delta$ cyaSL1344/pcDNA3.1-TsSP1.2, spleen and MLN cells were collected from three groups of mice and stimulated with rTsSP1.2. Cytokines in supernatants were quantified by ELISA. At day 10 after immunization, significant higher levels of IFN- $\gamma$ and IL-10 were observed in spleen and MLN cells from immunized mice with respect to empty plasmid pcDNA3.1 and PBS groups $(P<0.01)$ (Figure 4$)$. At days 20 and 30 after vaccination, levels of IFN- $\gamma$, IL-4 and IL-10 in spleen and MLN cells of immunized mice were evidently elevated relevant to the plasmid alone and PBS groups $(P<0.01)$, demonstrating that oral vaccination of $\Delta$ cyaSL1344/pcDNA3.1-TsSP1.2 elicited the concurrent Th1/Th2 immune responses.

\section{Intestinal mucosal immune response}

Total intestinal mucosal sIgA was assayed by a sandwich ELISA. TsSP1.2-specific sIgA was assayed by an indirect ELISA using rTsSP1.2-coated plates. Total intestinal sIgA level was obviously increased in mice vaccinated with $\Delta$ cyaSL1344/pcDNA3.1-TsSP1.2 and empty plasmid relative to those inoculated with only PBS (Figure 5A) $(F=93.815, P<0.01)$. Specific anti-TsSP1.2 sIgA was evidently elevated in mice vaccinated with TsSP1.2 DNA vaccine with respect to those inoculated with plasmid alone or only PBS $\left(\mathrm{t}_{\text {plasmid }}=54.551, \mathrm{t}_{\mathrm{PBS}}=63.619, P<0.01\right)$ (Figure $5 \mathrm{~B}$ ). No specific mucosal sIgA was detected in mice inoculated with empty plasmid or PBS only. 


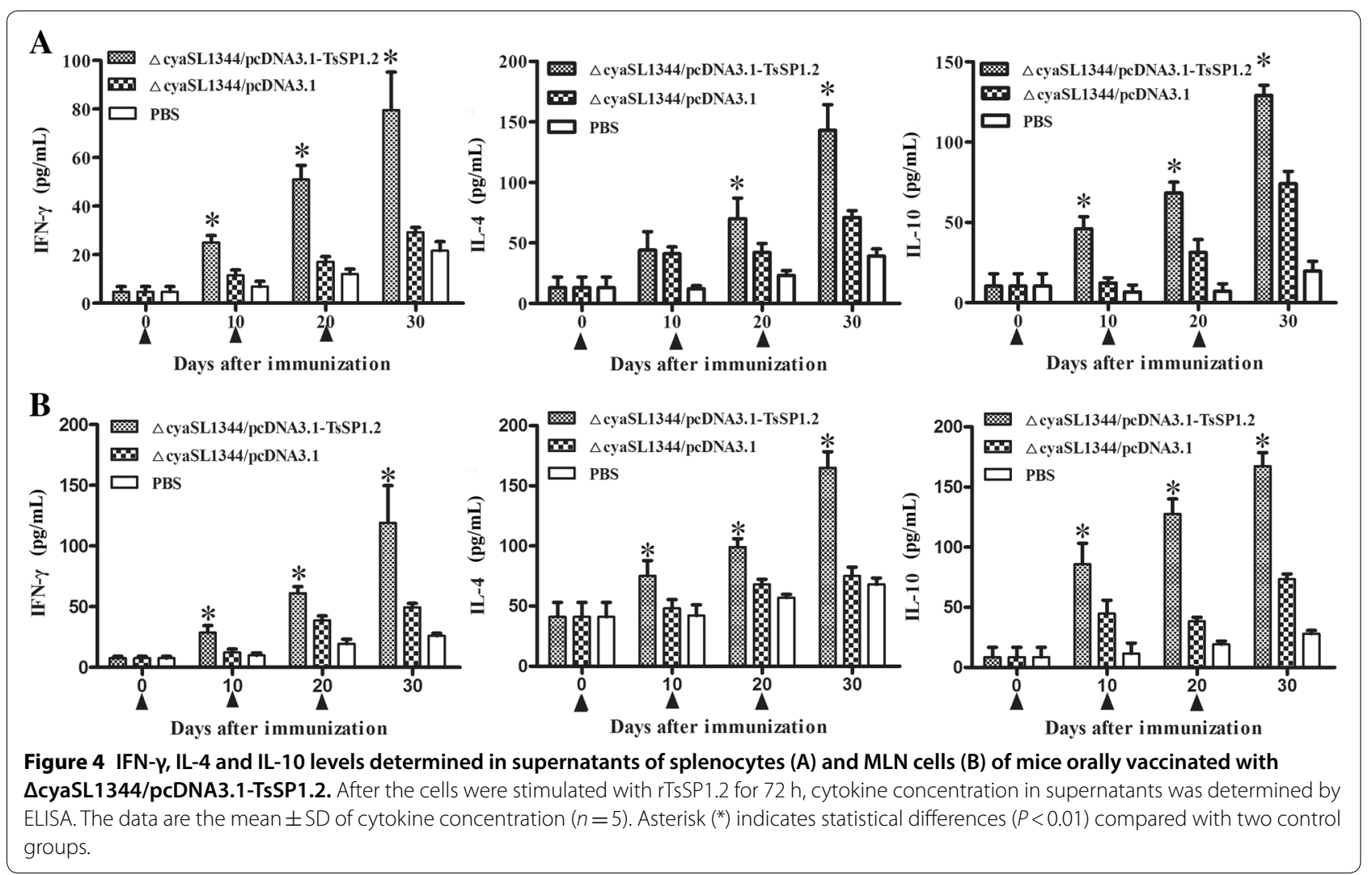

\section{Recognition of the native TsSP1.2 at different $T$. spiralis phases}

IFT analysis revealed that anti-rTsSP1.2 serum recognized the native TsSP1.2 on worm surface, fluorescent sign was homogenously distributed along the cuticle of various stages of T. spiralis (e.g., 3-24 h IIL, 3 and 5 day AW and ML) (Figure 6). When parasite sections were probed by anti-rTsSP1.2 serum, immunostaining was located at the cuticle and stichosome of IIL, AW, ML and embryos (Figure 7). Serum from mice inoculated with empty plasmid alone or PBS did not recognize any surface or internal components of the nematode. When intestinal anti-TsSP1.2 sIgA from immunized mice was used, the native TsSP1.2 was also detected on the surface of various stages of this nematode (Additional file 1). However, T. spiralis cuticles were not recognized by intestinal washings from mice inoculated with only empty plasmid or PBS.

\section{Immune protection against $T$. spiralis larval challenge}

The immune protection was investigated in vaccinated mice against challenge infection with $T$. spiralis ML. The results revealed that the mice vaccinated orally with $\Delta$ cyaSL1344/pcDNA3.1-TsSP1.2 produced a $33.45 \%$ reduction in intestinal adult recovery and $71.84 \%$ reduction in muscle larval recovery (Figure 8), compared to PBS control mice $\left(\mathrm{F}_{\text {adults }}=94.854, \mathrm{~F}_{\text {larvae }}=69.003, P=0\right)$. Additionally, the difference of adult burden $(t=7.842, P=0)$ and muscle larval burden $(t=5.057, P=0)$ between TsSP1.2 DNA vaccine and the empty plasmid group was statistically significant. The results indicate that a significant immune protection against $T$. spiralis challenge was elicited by oral vaccination of mice with TsSP1.2 DNA vaccine.

Furthermore, intestinal adult females collected from mice immunized with TsSP1.2 DNA vaccine were significantly smaller than those from mice inoculated only by plasmid or PBS control $\left(\mathrm{t}_{\text {plasmid }}=6.285 ; \mathrm{t}_{\mathrm{PBS}}=5.551\right.$, $P=0$ ) (Figure 9). The in vitro NBL production of adult females from mice immunized with TsSP1.2 vaccine was evidently lower than those from mice inoculated with plasmid alone or PBS control ( $t_{\text {plasmid }}=5.311$; $\left.\mathrm{t}_{\mathrm{PBS}}=4.986, P=0.001\right)$. Moreover, the NBL activity from the TsSP1.2 vaccine group becomes weaker with respect to two controls (Figure 10). The results indicate that larval growth and development and female fecundity were inhibited in immunized mice.

\section{Discussion}

Serine protease is one important family of proteases and plays a significant function in parasite infection [40, 41]. The proteolytic enzyme is involved in larval invasion, 


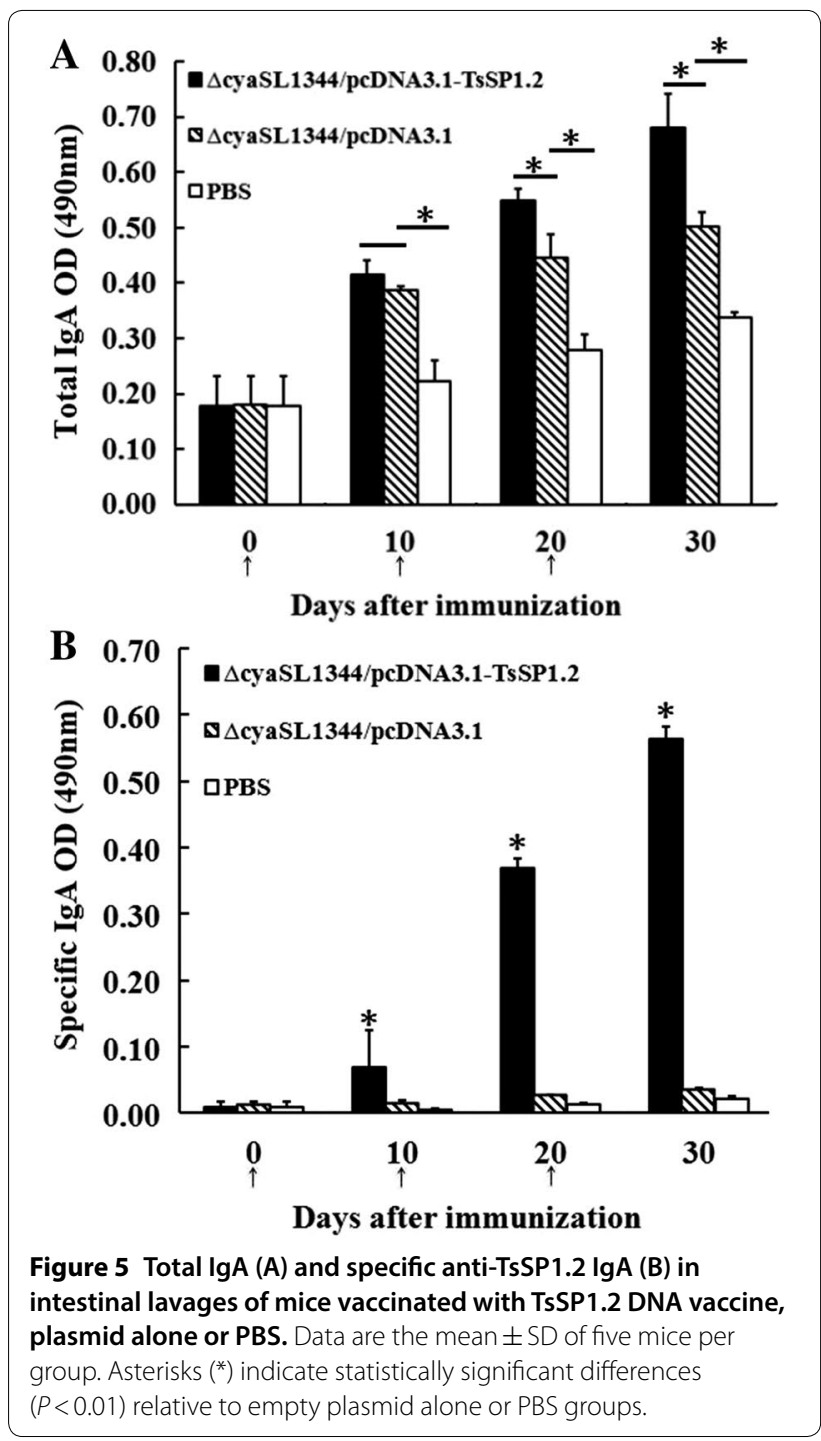

molting, and development [42]. Trichuris muris serine proteases degraded intestinal mucin Muc2 and destroy the mucus barrier [43]. Some T. spiralis serine proteases have been identified and characterized in ES proteins of ML, IIL and AW [16, 44, 45]. While the IIL invaded IEC, the expression level of IIL serine protease was significantly increased in comparison with the ML [46]. Monoclonal antibodies against T. spiralis TsSP1 inhibited the parasite invasion of IEC in vitro, indicating that TsSP might exert a principal function for degrading intestinal epithelial proteins and promoting larval invasion [47]. Subcutaneous vaccination of mice with rTsSP1.2 protein induced a $34.92 \%$ and $52.24 \%$ worm reduction of intestinal AW and muscle larvae, respectively [18]. The mice vaccinated with recombinant serine protease rTs-Adsp from T. spiralis adults showed a 46.5\% ML reduction

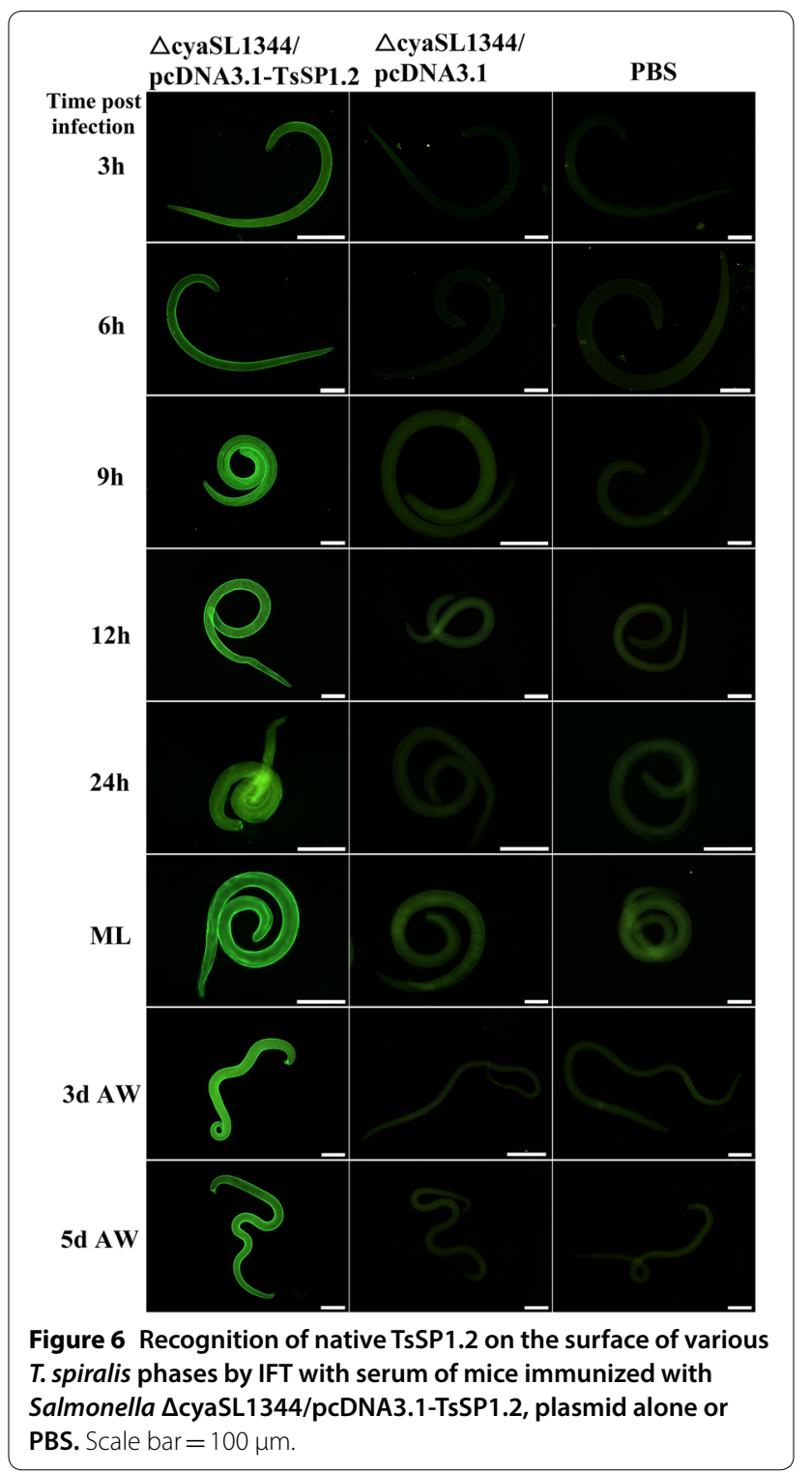

[48]. Immunization of mice by intramuscular injection of DNA vaccine from $T$. spiralis NBL serine protease exhibited a $77.93 \%$ larval reduction post challenge [39]. The results demonstrate that $T$. spiralis serine proteases participated in larval invasion of intestinal mucosa and could be deemed as anti-Trichinella vaccine target molecules.

Since trichinellosis is mainly due to the ingestion of infected meat, oral immunization is a more appropriate route to induce long intestinal protective immunity [13, 49]. Previous studies showed that attenuated Salmonella is an efficient live carrier for antigen delivery to elicit permanently persistent systemic and mucosal protective responses to the intestinal parasite stages, providing 


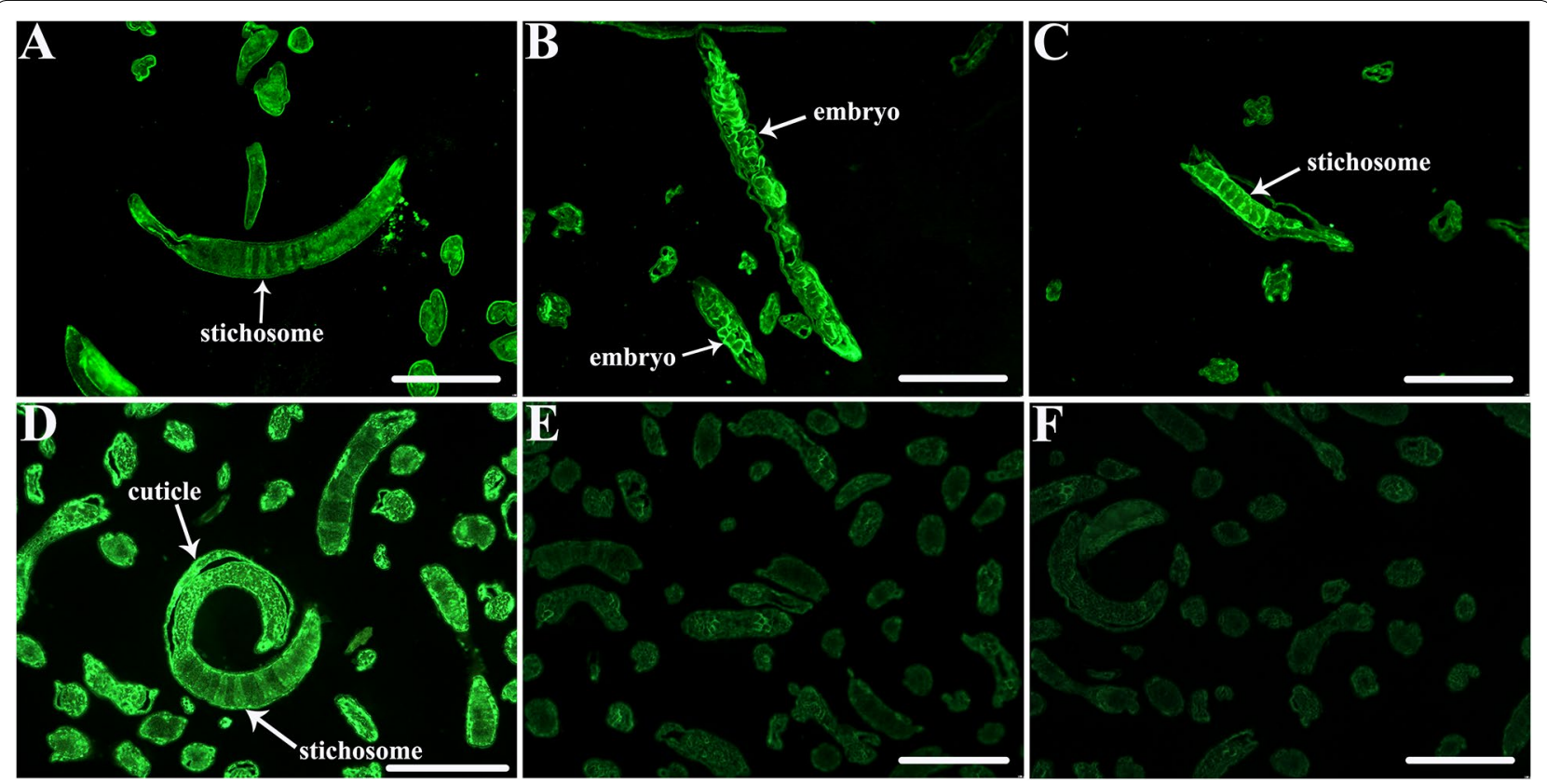

Figure 7 Immunolocalization of TsSP1.2 at $T$. spiralis various phases by IFT with serum of mice vaccinated with Salmonella $\Delta$ cyaSL1344/ pcDNA3.1-TsSP1.2, plasmid alone or PBS. The staining was located th the cuticle and stichosome of IIL (A), adult females (B, C), ML (D), and embryos in adult females (B). ML reveals no immunostaining with serum of mice inoculated with plasmid alone (E) or PBS (F) as negative control. Scale-bar $=100 \mu \mathrm{m}$.

a valid vaccination strategy by means of oral or intranasal routes [50,51]. Intestinal mucosal IgA response and secretory IgA (sIgA) cells returning to intestinal epithelium could be effectively elicited by oral vaccination of the attenuated Salmonella, the sIgA has crucial roles for expelling or sacrificing intestinal parasites [52]. An oral Ts87 DNA/S. typhimurium vaccine showed protection against T. spiralis challenge as demonstrated by a $29.8 \%$ and $34.2 \%$ worm reduction of AW and ML in a mouse model [26]. Oral vaccination of mice with $T$. spiralis paramyosin (TsPmy) DNA/S. typhimurium induces a $44.8 \%$ and $46.6 \%$ reduction of AW and ML in vaccinated mice [30]. Intranasal immunization of mice with attenuated Salmonella carrying T. spiralis gp43 antigen-derived 30 -mer epitope (Ag30) produces a $61.83 \%$ reduction of adult burden at $8 \mathrm{dpi}$; when the attenuated Salmonella vaccine that secretes Ag30 combined with adjuvant C3dP28 was used, the adult reduction was up to $92.8 \%$ following challenge [31,33].

In our study, to enhance the efficacy of TsSP1.2 vaccination, oral vaccination with T. spiralis TsSP1.2 DNA delivered through attenuated S. typhimurium shows a significant immune protection against challenge in vaccinated mice. This protection exhibited obvious reductions of intestinal adult and muscle larval burdens. The attenuated Salmonella is a live vector in which the target DNA can be carried to local and systemic lymph tissues [53]. The TsSP1.2 mRNA and rTsSP1.2 protein in spleens and MLN of immunized mice were detected by RT-PCR and IFT, indicating that the TsSP1.2 gene was transcribed and expressed in mice after vaccination with TsSP1.2 DNA/S. typhimurium vaccine. Oral vaccination with attenuated Salmonella-delivered TsSP1.2 DNA trigged evidently not only local intestinal mucosal sIgA responses but also systemic immune responses. The sIgA exerts a key function in intestinal defense and blocking of parasite invasion of intestinal epithelium. The sIgA against adult surface antigens mediated intestinal adult worm expulsion, passive transfer of McAb IgA against Trichinella to naive mice produced $95 \%$ protection against larval challenge infection $[54,55]$. Besides, the protection might be due to the formation of anti-T. spiralis antibody immune complex in the larval head, which may physically block larval direct contact with IEC, therefore protecting intestinal mucosa from larval invasion $[18,56,57]$. Our results reveal that immunized mice produced the TsSP1.2-specific intestinal sIgA, and serum IgG, which recognized the native TsSP1.2 on the surface or secreted by various $T$. spiralis stages. The sIgA is Th2-dependent, especially IL-4 and IL-10 are the main cytokines which strengthen SIgA responses [58], suggesting that IL-4 as well as IL-10 may also enhance intestinal sIgA response. 


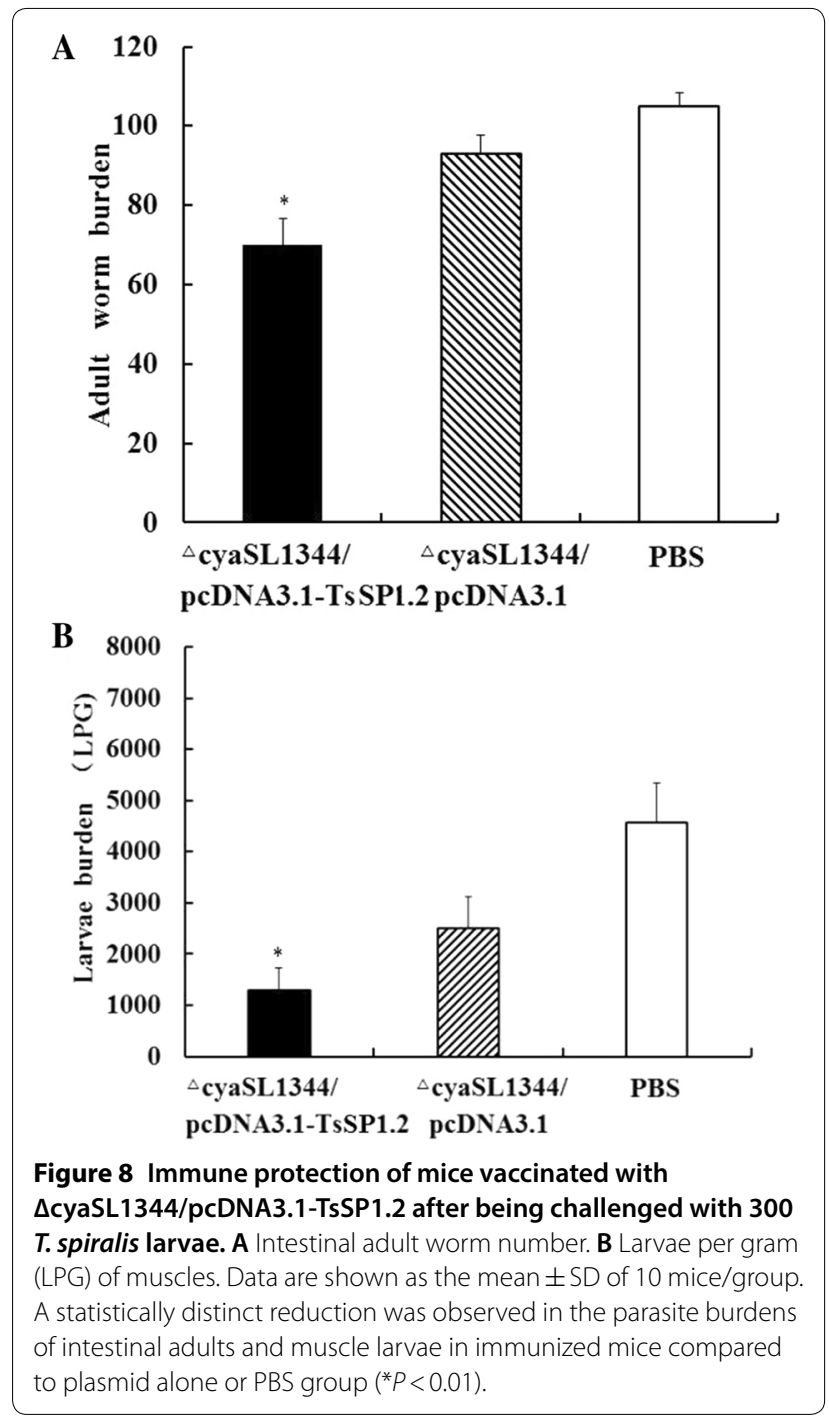

Additionally, intestinal sIgA could also inhibit the female worm fecundity, reduce adult size and block larval establishment in intramulticellular niches of intestinal mucosal columnar epithelium [33, 59]. Our results reveal that the length of adult females recovered from immunized mice and their fecundity (the in vitro NBL production of females in $72 \mathrm{~h}$ ) were significantly lower than those from empty plasmid alone or PBS groups. The results suggest that TsSP1.2-specific intestinal sIgA inhibited the intestinal worm growth and reduced female fecundity, since female uterus length is related to reproductive capacity index, i.e., the shorter the uterus, the lower the intrauterine larval capacity and reproductive capacity index $[60,61]$. TsSP1.2 might be a pivotal protease related to the larval invasion of the host's intestinal mucosa. The high levels of TsSP1.2-specific IgG and sIgA produced by oral vaccination with rTsSP1.2 might inhibit larval invasion and development, and reduce female

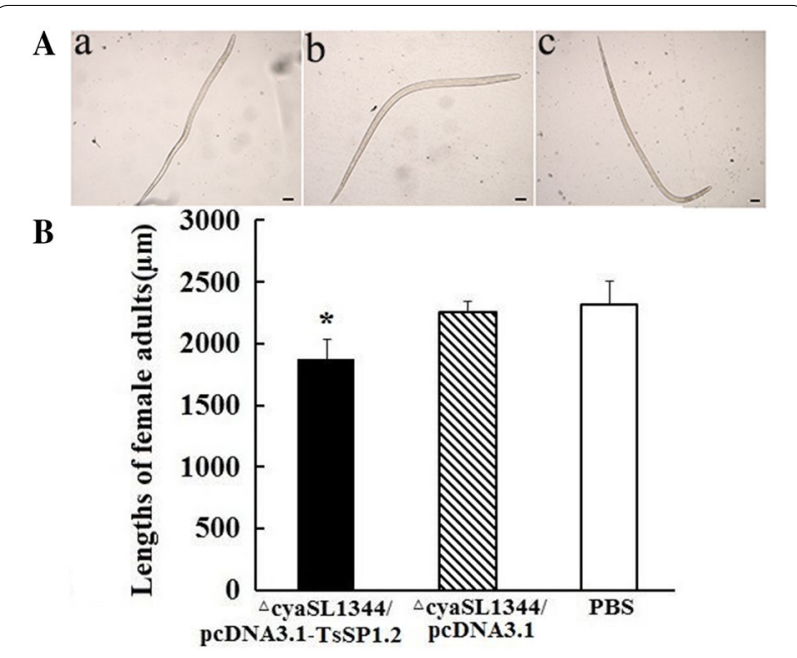

Figure 9 T. spiralis adult females collected from mice vaccinated with $\Delta$ cyaSL1344/pcDNA3.1-TsSP1.2 at 7 days after challenge. A Morphology of T. spiralis adult females (Scale bar $=100 \mu \mathrm{m}$ ) from mice vaccinated with $\triangle$ cyaSL1344/pcDNA3.1-TsSP1.2 (a), $\triangle$ cyaSL1344/ pcDNA3.1 alone (b) and only PBS (c) groups. B The mean length \pm SD of 10 adult females from each group. Asterisk demonstrates an evident differences $(P<0.01)$ in female length relative to the two control groups.

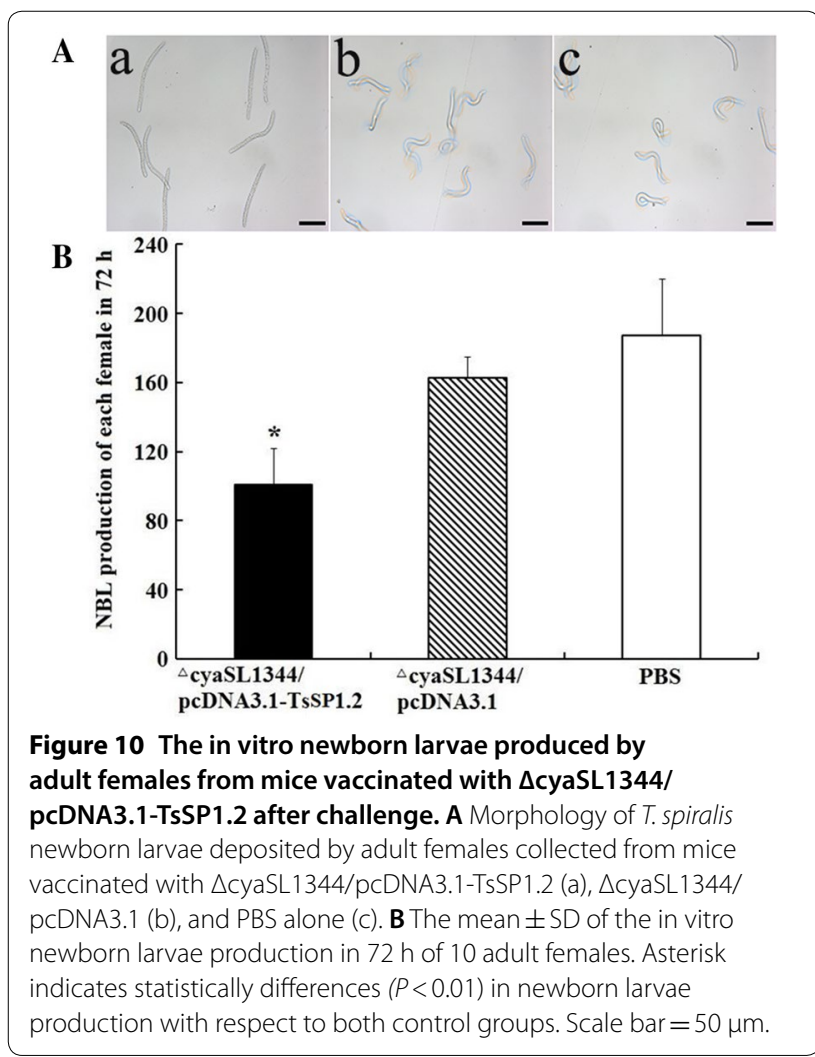


fecundity [57, 59, 62]. Furthermore, anti-TsSP1.2 antibodies might take part in the killing of newborn larvae by an ADCC-mediated mechanism [63]. Therefore, oral vaccination with TsSP1.2 DNA vaccine produced a significant reduction of muscle larva burden in immunized mice.

Humoral immune responses revealed that serum IgG1 levels were more obviously higher than those of IgG2a on days 20 and 30 after oral vaccination with TsSP1.2 DNA, but IgG2a was also elicited following vaccination, suggesting that the mixed Th1/ Th2 immune response was triggered with immunization with TsSP1.2 DNA/S. typhimurium. The mixed immune response was further verified by higher levels of Th1 (IFN- $\gamma$ ) and Th2 cytokines (IL-4 and IL-10) after spleen and MLN cells of immunized mice were stimulated by rTsSP1.2 protein. The mixed Th1/Th2 immune response is important for immune protection against larval challenge infection [33, 64]. Helminth infections are usually associated with Th2-type immune response characterized by the activation of CD4+ T helper cells and secretion of IL-4, IL-5, IL-9 and IL-13. The Th2type cytokines are important for intestinal $T$. spiralis adult worm expulsion, which is regulated mainly by Th2-type cytokines and depends on IL-4/IL-13 production; when they are inhibited, the parasite survival is extended [13, 65]. Additionally, Th2-type cytokines also activate macrophages that mediate the host defense against the nematode infection.

Since T. spiralis is a multicellular parasitic nematode with complicated antigenicity, the immune responses elicited by vaccination with a single recombinant protein molecule might not be enough to confront challenge infection [13]. Vaccination of mice with TsSP1.2 DNA/S. typhimurium produced a partial immune protection. Consequently, to improve the protective efficacy, oral polyvalent vaccines against different $T$. spiralis invasive stages need to be further exploited [9, 33, 39, 66]. Additionally, different adjuvants may elicit different immune protection, the adjuvants (e.g., Montanide, nanoparticles or Th2 cytokine) and other administration means (intranasal route) should also be attempted to induce better immune protection with rTsSP1.2 [67, 68].

In conclusion, our results demonstrate that a concurrent $T h 1 / T h 2$ immune response and intestinal mucosal IgA response were elicited by oral vaccination with attenuated Salmonella-delivered TsSP1.2 DNA vaccine. The immunized mice show an evident immune protection against $T$. spiralis challenge as demonstrated by a $33.45 \%$ reduction of intestinal adult worms and $71.84 \%$ reduction of muscle larvae. The protection might be due to $\mathrm{rTsSP} 1.2$-induced production of specific anti-TsSP1.2
sIgA, IgG, IgG1/IgG2a, and secretion of IFN- $\gamma$, IL-4 and IL-10, which could protect intestinal mucosa from the parasite invasion, inhibit worm development and reduce female fecundity. The attenuated Salmonella-delivered rTsSP1.2 DNA offers a prospective strategy for the prevention and control of animal Trichinella infection.

\section{Additional file}

Additional file 1. Recognition of the native TsSP1.2 on surface of different $T$. spiralis phases by IFT with intestinal washes from mice vaccinated with $\Delta$ cyaSL1344/pcDNA3.1-TsSP1.2, empty plasmid or PBS. Scale bar $=50 \mu \mathrm{m}$.

\section{Abbreviations}

AW: adult worms; BHK: baby hamster kidney cells; dpi: days post-infection; ES: excretory-secretory; IEC: intestinal epithelial cell; IFT: immunofluorescent test; IIL: intestinal infective larvae; LPG: larvae per gram; MBP: maltose-binding protein; ML: muscle larvae; MLN: mesenteric lymph nodes; NBL: newborn larvae; OPD: o-phenylenediamine dihydrochloride; ORF: open reading frame; SD: standard deviation; slgA: secretory IgA; SPF: specific pathogen-free; TsSP: T. spiralis serine protease.

\section{Competing interests}

The authors declare that they have no competing interests.

\section{Authors' contributions}

ZQW and JC designed this study. JFL, KXG, XQ, JJL, YH, SWY, and PJ performed the experiments. $C Y$ and XCC provided the attenuated S. typhimurium $\Delta$ cyaSL1344 strain. JFL analyzed the data with the aid of PJ and XQ. JFL, ZQW and JC drafted the manuscript. All authors read and approved the final manuscript.

\section{Acknowledgements}

This study was supported by grants of the National Key Research and Development Program of China (2017YFD0501302) and the National Natural Science Foundation of China (nos. U1704284 and 81471981). We thank Ge Ge Sun, Hua Nan Ren, Yan Yan Song, and Shao Rong Long for their technical assistance.

\section{Ethics approval and consent to participate}

All animal care and use in this study were approved by the Life Science Ethics Committee of Zhengzhou University (No. SCXK 2015-0005).

\section{Author details \\ ${ }^{1}$ Department of Parasitology, Medical College, Zhengzhou University, Zheng- zhou 450052, China. ${ }^{2}$ Key Lab of Animal Disease and Public Health, College of Animal Science and Technology, Henan University of Science and Technol- ogy, Luoyang 471003, China.}

\section{Publisher's Note}

Springer Nature remains neutral with regard to jurisdictional claims in published maps and institutional affiliations.

Received: 9 June 2018 Accepted: 9 July 2018

Published online: 06 September 2018

References

1. Murrell KD, Pozio E (2011) Worldwide occurrence and impact of human trichinellosis, 1986-2009. Emerg Infect Dis 17:2194-2202 
2. Costantino SN, Sosa N, Calcagno MA, Forastiero MA, Farabello SP, Taus MR, Venturiello SM (2009) Detection of trichinellosis in a historically Trichinella-free area of Argentina. Vet Parasitol 159:354-357

3. Cui J, Jiang P, Liu LN, Wang ZQ (2013) Survey of Trichinella infections in domestic pigs from northern and eastern Henan, China. Vet Parasitol 194:133-135

4. Jiang P, Zhang X, Wang LA, Han LH, Yang M, Duan JY, Sun GG, Qi X, Liu RD, Wang ZQ, Cui J (2016) Survey of Trichinella infection from domestic pigs in the historical endemic areas of Henan province, central China. Parasitol Res 115:4707-4709

5. Ng-Nguyen D, Stevenson MA, Traub RJ (2017) A systematic review of taeniasis, cysticercosis and trichinellosis in Vietnam. Parasit Vectors 10:150

6. Cui J, Wang ZQ, Xu BL (2011) The epidemiology of human trichinellosis in China during 2004-2009. Acta Trop 118:1-5

7. Rostami A, Gamble HR, Dupouy-Camet J, Khazan H, Bruschi F (2017) Meat sources of infection for outbreaks of human trichinellosis. Food Microbiol 64:65-71

8. Bai X, Hu X, Liu X, Tang B, Liu M (2017) Current research of Trichinellosis in China. Front Microbiol 8:1472

9. GuY, Sun X, Li B, Huang J, Zhan B, Zhu X (2017) Vaccination with a paramyosin-based multi-epitope vaccine elicits significant protective immunity against Trichinella spiralis infection in mice. Front Microbiol 8:1475

10. Liu P, Wang ZQ, Liu RD, Jiang P, Long SR, Liu LN, Zhang XZ, Cheng XC, Yu C, Ren HJ, Cui J (2015) Oral vaccination of mice with Trichinella spiralis nudix hydrolase DNA vaccine delivered by attenuated Salmonella elicited protective immunity. Exp Parasitol 153:29-38

11. Liu RD, Wang ZQ, Wang L, Long SR, Ren HJ, Cui J (2013) Analysis of differentially expressed genes of Trichinella spiralis larvae activated by bile and cultured with intestinal epithelial cells using real-time PCR. Parasitol Res 112:4113-4120

12. Wang ZQ, Liu RD, Sun GG, Song YY, Jiang P, Zhang X, Cui J (2017) Proteomic analysis of Trichinella spiralis adult worm excretory-secretory proteins recognized by sera of patients with early Trichinellosis. Front Microbiol 8:986

13. Ortega-Pierres G, Vaquero-Vera A, Fonseca-Linan R, Bermudez-Cruz RM, Arguello-Garcia R (2015) Induction of protection in murine experimental models against Trichinella spiralis: an up-to-date review. J Helminthol 89:526-539

14. Cui J, Liu RD, Wang L, Zhang X, Jiang P, Liu MY, Wang ZQ (2013) Proteomic analysis of surface proteins of Trichinella spiralis muscle larvae by twodimensional gel electrophoresis and mass spectrometry. Parasit Vectors 6:355

15. Liu RD, Cui J, Liu XL, Jiang P, Sun GG, Zhang X, Long SR, Wang L, Wang ZQ (2015) Comparative proteomic analysis of surface proteins of Trichinella spiralis muscle larvae and intestinal infective larvae. Acta Trop 150:79-86

16. Liu RD, Jiang P, Wen H, Duan JY, Wang LA, Li JF, Liu CY, Sun GG, Wang ZQ Cui J (2016) Screening and characterization of early diagnostic antigens in excretory-secretory proteins from Trichinella spiralis intestinal infective larvae by immunoproteomics. Parasitol Res 115:615-622

17. Wang L, Cui J, Hu DD, Liu RD, Wang ZQ (2014) Identification of early diagnostic antigens from major excretory-secretory proteins of Trichinella spiralis muscle larvae using immunoproteomics. Parasit Vectors 7:40

18. Wang B, Wang ZQ, Jin J, Ren HJ, Liu LN, Cui J (2013) Cloning, expression and characterization of a Trichinella spiralis serine protease gene encoding a $35.5 \mathrm{kDa}$ protein. Exp Parasitol 134:148-154

19. Gamble HR, Bessonov AS, Cuperlovic K, Gajadhar AA, van Knapen F, Noeckler K, Schenone H, Zhu X (2000) International Commission on Trichinellosis: recommendations on methods for the control of Trichinella in domestic and wild animals intended for human consumption. Vet Parasitol 93:393-408

20. Li F, Wang ZQ, Cui J (2010) Early detection by polymerase chain reaction of migratory Trichinella spiralis larvae in blood of experimentally infected mice. Foodborne Pathog Dis 7:887-892

21. Sun GG, Wang ZQ, Liu CY, Jiang P, Liu RD, Wen H, Qi X, Wang L, Cui J (2015) Early serodiagnosis of trichinellosis by ELISA using excretory-secretory antigens of Trichinella spiralis adult worms. Parasit Vectors 8:484

22. Wu Z, Nagano I, Takahashi Y, Maekawa Y (2016) Practical methods for collecting Trichinella parasites and their excretory-secretory products. Parasitol Int 65:591-595
23. Yang $W$, Li LG, Liu RD, Sun GG, Liu CY, Zhang SB, Jiang P, Zhang X, Ren HJ, Wang ZQ, Cui J (2015) Molecular identification and characterization of Trichinella spiralis proteasome subunit beta type-7. Parasit Vectors 8:18

24. Liu P, Cui J, Liu RD, Wang M, Jiang P, Liu LN, Long SR, Li LG, Zhang SB, Wang ZQ (2015) Protective immunity against Trichinella spiralis infection induced by TsNd vaccine in mice. Parasit Vectors 8:185

25. Liu CY, Song YY, Ren HN, Sun GG, Liu RD, Liu LN, Long SR, Li LG, Zhang SB, Wang ZQ (2017) Cloning and expression of a Trichinella spiralis putative glutathione $\mathrm{S}$-transferase and its elicited protective immunity against challenge infections. Parasit Vectors 10:448

26. Yang Y, Zhang Z, Yang J, Chen X, Cui S, Zhu X (2010) Oral vaccination with Ts87 DNA vaccine delivered by attenuated Salmonella typhimurium elicits a protective immune response against Trichinella spiralis larval challenge. Vaccine 28:2735-2742

27. Liu XD, Wang XL, Bai X, Liu XL, Wu XP, Zhao Y, Sun SM, Yu L, Su XZ, Wang ZQ, Wang F, Liu MY (2014) Oral administration with attenuated Salmonello encoding a Trichinella cystatin-like protein elicited host immunity. Exp Parasitol 141:1-11

28. Li LG, Wang ZQ, Liu RD, Yang X, Liu LN, Sun GG, Jiang P, Xi Zhang, Zhang GY, Cui J (2015) Trichinella spiralis: low vaccine potential of glutathione S-transferase against infections in mice. Acta Trop 146:25-32

29. Long SR, Wang ZQ, Liu RD, Liu LN, Li LG, Jiang P, Zhang X, Zhang ZF, Shi HN, Cui I (2014) Molecular identification of Trichinella spiralis nudix hydrolase and its induced protective immunity against trichinellosis in BALB/C mice. Parasit Vectors 7:600

30. Wang L, Wang X, Bi K, Sun X, Yang J, Gu Y, Huang J, Zhan B, Zhu X (2016) Oral vaccination with attenuated Salmonella typhimurium-delivered TsPmy DNA vaccine elicits protective immunity against Trichinella spiralis in BALB/c mice. PLoS Negl Trop Dis 10:e0004952

31. Pompa-Mera EN, Yepez-Mulia L, Ocana-Mondragon A, Garcia-Zepeda EA, Ortega-Pierres G, González-Bonilla CR (2011) Trichinella spiralis: intranasal immunization with attenuated Salmonella enterica carrying a gp43 antigen-derived 30-mer epitope elicits protection in BALB/c mice. Exp Parasitol 129:393-401

32. Sun GG, Song YY, Jiang P, Ren HN, Yan SW, Han Y, Liu RD, Zhang X, Wang ZQ, Cui J (2018) Characterization of a Trichinella spiralis putative serine protease. Study of its potential as sero-diagnostic tool. PLoS Negl Trop Dis 12:e0006485

33. Pompa-Mera EN, Arroyo-Matus P, Ocana-Mondragon A, GonzalezBonilla CR, Yepez-Mulia L (2014) Protective immunity against enteral stages of Trichinella spiralis elicited in mice by live attenuated Salmonella vaccine that secretes a 30-mer parasite epitope fused to the molecular adjuvant C3d-P28. Res Vet Sci 97:533-545

34. Zhang Y, Wang Z, Li L, Cui J (2013) Molecular characterization of Trichinella spiralis aminopeptidase and its potential as a novel vaccine candidate antigen against trichinellosis in BALB/C mice. Parasit Vectors $6: 246$

35. Cui J, Ren HJ, Liu RD, Wang L, Zhang ZF, Wang ZQ (2013) Phage-displayed specific polypeptide antigens induce significant protective immunity against Trichinella spiralis infection in BALB/c mice. Vaccine 31:1171-1177

36. Zhang $S B$, Jiang $P$, Wang ZQ, Long SR, Liu RD, Zhang X, Yang W, Ren HJ, Cui J (2016) DsRNA-mediated silencing of Nudix hydrolase in Trichinella spiralis inhibits the larval invasion and survival in mice. Exp Parasitol 162:35-42

37. Li F, Cui J, Wang ZQ, Jiang P (2010) Sensitivity and optimization of artificial digestion in the inspection of meat for Trichinella spiralis. Foodborne Pathog Dis 7:879-885

38. Gu Y, Wei J, Yang J, Huang J, Yang X, Zhu X (2013) Protective immunity against Trichinella spiralis infection induced by a multi-epitope vaccine in a murine model. PLoS One 8:e77238

39. Xu J, Bai X, Wang LB, Shi HN, Van Der Giessen JW, Boireau P, Liu MY, Liu $X L$ (2017) Immune responses in mice vaccinated with a DNA vaccine expressing serine protease-like protein from the new-born larval stage of Trichinella spiralis. Parasitology 144:712-719

40. Hedstrom L (2002) Serine protease mechanism and specificity. Chem Rev 102:4501-4524

41. Yang Y, Wen Y, Cai YN, Vallee I, Boireau P, Liu MY, Cheng SP (2015) Serine proteases of parasitic helminths. Korean J Parasitol 53:1-11

42. Nagano I, Wu Z, Nakada T, Boonmars T, Takahashi Y (2003) Molecular cloning and characterization of a serine proteinase gene of Trichinella spiralis. J Parasitol 89:92-98 
43. Hasnain SZ, McGuckin MA, Grencis RK, Thornton DJ (2012) Serine protease(s) secreted by the nematode Trichuris muris degrade the mucus barrier. PLoS Negl Trop Dis 6:e1856

44. Robinson MW, Connolly B (2005) Proteomic analysis of the excretorysecretory proteins of the Trichinella spiralis L1 larva, a nematode parasite of skeletal muscle. Proteomics 5:4525-4532

45. Todorova VK, Knox DP, Kennedy MW (1995) Proteinases in the excretory/secretory products (ES) of adult Trichinella spiralis. Parasitology 111:201-208

46. Ren HJ, Cui J, Yang W, Liu RD, Wang ZQ (2013) Identification of differentially expressed genes of Trichinella spiralis larvae after exposure to host intestine milieu. PLoS One 8:e67570

47. Romaris F, North SJ, Gagliardo LF, Butcher BA, Ghosh K, Beiting DP, Panico M, Arasu P, Dell A, Morris HR, Appleton JA (2002) A putative serine protease among the excretory-secretory glycoproteins of L1 Trichinella spiralis. Mol Biochem Parasitol 122:149-160

48. Feng S, Wu X, Wang X, Bai X, Shi H, Tang B, Liu X, Song Y, Boireau P, Wang $F$, Zhao Y, Liu M (2013) Vaccination of mice with an antigenic serine protease-like protein elicits a protective immune response against Trichinella spiralis infection. J Parasitol 99:426-432

49. Dea-Ayuela MA, Rama-Iniguez S, Bolas-Fernandez F (2006) Vaccination of mice against intestinal Trichinella spiralis infections by oral administration of antigens microencapsulated in methacrilic acid copolymers. Vaccine 24:2772-2780

50. Darji A, Zur Lage S, Garbe Al, Chakraborty T, Weiss S (2000) Oral delivery of DNA vaccines using attenuated Salmonella typhimurium as carrier. FEMS Immunol Med Microbiol 27:341-349

51. Castillo Alvarez AM, Vaquero-Vera A, Fonseca-Linan R, Ruiz-Perez F, Villegas-Sepulveda N, Ortega-Pierres G (2013) A prime-boost vaccination of mice with attenuated Salmonella expressing a 30-mer peptide from the Trichinella spiralis gp43 antigen. Vet Parasitol 194:202-206

52. Mantis NJ, Rol N, Corthesy B (2011) Secretory IgA's complex roles in immunity and mucosal homeostasis in the gut. Mucosal Immunol 4:603-611

53. Lin IY, Van TT, Smooker PM (2015) Live-attenuated bacterial vectors: tools for vaccine and therapeutic agent delivery. Vaccines (Basel) 3:940-972

54. Inaba T, Sato H, Kamiya H (2003) Impeded establishment of the infective stage of Trichinella in the intestinal mucosa of mice by passive transfer of an IgA monoclonal antibody. J Vet Med Sci 65:1227-1231

55. Inaba T, Sato H, Kamiya H (2003) Monoclonal IgA antibody-mediated expulsion of Trichinella from the intestine of mice. Parasitology 126:591-598
56. McVay CS, Tsung A, Appleton J (1998) Participation of parasite surface glycoproteins in antibody-mediated protection of epithelial cells against Trichinella spiralis. Infect Immun 66:1941-1945

57. McVay CS, Bracken P, Gagliardo LF, Appleton J (2000) Antibodies to tyvelose exhibit multiple modes of interference with the epithelial niche of Trichinella spiralis. Infect Immun 68:1912-1918

58. Yamamoto M, Vancott JL, Okahashi N, Marinaro M, Kiyono H, Fujihashi K, Jackson RJ, Chatfield SN, Bluethmann H, McGhee JR (1996) The role of Th1 and Th2 cells for mucosal IgA responses. Ann N Y Acad Sci 778:64-71

59. Robinson K, Bellaby T, Wakelin D (1995) Oral and parenteral vaccination against Trichinella spiralis infections in high- and low-responder mice. Int J Parasitol 25:989-992

60. Murrell KD, Lichtenfels RJ, Zarlenga DS, Pozio E (2000) The systematics of the genus Trichinella with a key to species. Vet Parasitol 93:293-307

61. Pozio E, Darwin Murrell K (2006) Systematics and epidemiology of Trichinella. Adv Parasitol 63:367-439

62. Liu CY, Ren HN, Song YY, Sun GG, Liu RD, Jiang P, Long SR, Zhang X, Wang ZQ Cui J (2018) Characterization of a putative glutathione S-transferase from the parasitic nematode Trichinella spiralis. Exp Parasitol 187:59-66

63. Sun GG, Ren HN, Liu RD, Song YY, Qi X, Hu CX, Yang F, Jiang P, Zhang X, Wang ZQ, Cui J (2018) Molecular characterization of a putative serine protease from Trichinella spiralis and its elicited immune protection. Vet Res 49:59

64. Song YY, Wang LA, Ren HN, Qi X, Sun GG, Liu RD, Jiang P, Zhang X, Cui J, Wang ZQ (2018) Cloning, expression and characterization of a cysteine protease from Trichinella spiralis. Folia Parasitol 65(2018):007

65. Zhang N, Li W, Fu B (2018) Vaccines against Trichinella spiralis: progress, challenges and future prospects. Transbound Emerg Dis. https://doi. org/10.1111/tbed.12917

66. Song YY, Zhang Y, Yang DQ, Ren HN, Sun GG, Liu RD, Jiang P, Zhang X, Cui J. Wang ZQ (2018) The immune protection induced by a serine protease inhibitor from Trichinella spiralis. Front Microbiol 9:1544

67. Xu J, Bai X, Wang LB, Shi HN, van der Giessen JWB, Boireau P, Liu MY, Liu XL (2017) Influence of adjuvant formulation on inducing immune response in mice immunized with a recombinant serpin from Trichinella spiralis. Parasite Immunol. https://doi.org/10.1111/pim.12437

68. Xu J, Yang F, Yang DQ, Jiang P, Liu RD, Zhang X, Cui J, Wang ZQ (2018) Molecular characterization of Trichinella spiralis galectin and its participation in larval invasion of host's intestinal epithelial cells. Vet Res 49:79

Ready to submit your research? Choose BMC and benefit from

- fast, convenient online submission

- thorough peer review by experienced researchers in your field

- rapid publication on acceptance

- support for research data, including large and complex data types

- gold Open Access which fosters wider collaboration and increased citations

- maximum visibility for your research: over $100 \mathrm{M}$ website views per year

At BMC, research is always in progress.

Learn more biomedcentral.com/submissions 